\title{
Teachers' digital competencies in higher education: a systematic literature review
}

\author{
Verónica Basilotta-Gómez-Pablos ${ }^{1}$, María Matarranz ${ }^{1 *}$ [D, Luis-Alberto Casado-Aranda ${ }^{2}$ and Ana Otto ${ }^{1}$
}

\author{
${ }^{*}$ Correspondence: \\ maria.matarranz@udima.es \\ ${ }^{1}$ Facultad de Ciencias de \\ la Salud y la Educación, \\ Departamento de Educación, \\ Universidad a Distancia \\ de Madrid, Vía de Servicio \\ A-6, 15, Collado Villalba, \\ 28400 Madrid, Spain \\ Full list of author information \\ is available at the end of the \\ article
}

\begin{abstract}
Digital competence has gained a strong prominence in the educational context, being one of the key competencies that teachers must master in today's society. Although most models and frameworks focus on the pre-university level, there is a growing interest in knowing the state of digital competencies of university teachers, that is, the set of knowledge, skills and attitudes necessary for a teacher to make effective use of technologies. The aim of this research is to present a systematic review of the literature in the Web of Science and Scopus, to identify, analyze and classify the published articles between 2000 and 2021 on digital competences, and thus find and improve the research being done on digital skills and future avenues of teachers in the university context. The SciMAT software is used in the analysis. The initial search reveals more than 343 articles in English, of which 152 are duplicates and 135 are not related to the topic of study. After this filtering, 56 articles are obtained and analyzed in depth. The results reveal a predominance of research that focuses on analyzing teachers' self-assessment and reflection of their digital competencies. Teachers recognize that they have a low or medium-low digital competence, as well as the absence of certain competencies, especially those related to the evaluation of educational practice. Despite the multiple studies that address this issue, it is necessary to continue improving research in this area, deepening the assessment of teachers' digital competencies and design, on this basis, more practical and personalized training programs that respond to the needs of teachers in the digital era.
\end{abstract}

Keywords: Digital competence, University education, Teacher professional competence, Bibliometric indicators

\section{Introduction}

The origin of the teaching and learning by competencies approach is the result of the social changes that we have been living in the last decades. However, it has not been until the more recent years that we are witnessing how globalization is rapidly expanding. In fact, the constant renewal of Information and Communication Technologies (ICT), the exponential creation of information, the use of different resources and digital media and their unprecedented consumption, the demand for educational platforms that allow distance teaching and learning or the urgent adaptation of face-to-face teaching to the recently called emergency remote teaching (ERT) (Trust \& Whalen, 2020) derived from the COVID-19 health crisis, are some of the clearest examples of this digital revolution.

(c) The Author(s), 2022. Open Access This article is licensed under a Creative Commons Attribution 4.0 International License, which permits use, sharing, adaptation, distribution and reproduction in any medium or format, as long as you give appropriate credit to the original author(s) and the source, provide a link to the Creative Commons licence, and indicate if changes were made. The images or other third party material in this article are included in the article's Creative Commons licence, unless indicated otherwise in a credit line to the material. If material is not included in the article's Creative Commons licence and your intended use is not permitted by statutory regulation or exceeds the permitted use, you will need to obtain permission directly from the copyright holder. To view a copy of this licence, visit http:// creativecommons.org/licenses/by/4.0/. 
Given this reality, digital competence has gained a strong prominence in the educational context in recent times (Tejada \& Pozos, 2018). On the one hand, because the use of technology has become an everyday occurrence; on the other hand, because the professional development of many citizens depends largely (and increasingly) on an efficient and appropriate use of ICT. In this regard, Cabero et al., (2020) point out that digital competence is one of the key competencies that citizens in general, and teachers specifically, must master in the society of the future. In fact, in Spain, the recent National Plan of Digital Competences (MINECO, 2021) identifies the acquisition of Teachers Digital Competencies (hereinafter, TDC) at all educational levels, including the university as one of its main strategic axes, which is aimed at promoting sustainable and inclusive economic growth. The teacher is key in such process of integrating technologies and plays a crucial role in the adoption and implementation of ICT in the classroom, since the transformation and improvement of education will depend, among other aspects, on educational action, which implies that teachers must have effective digital competencies that allow them to integrate and use technologies in a pedagogical way.

Particularly, The EU defines digital competence as:

"the safe, critical and responsible use of and interaction with digital technologies for learning, at work and for participation in society. It includes information and data literacy, communication and collaboration, media literacy, digital content creation (including programming), security (including digital well-being and cybersecurityrelated skills), intellectual property issues, problem solving and critical thinking." (Council of the European Union, 2018, p. 9)

For their part, the definitions of the term TDC are varied, although we find coincidences in fundamental aspects that emphasize the need for teachers to have didactic and technological knowledge that allow them to make use of digital technologies in their professional practice, the latter being understood in a broad sense (Silva et al., 2018). Durán (2019) further points out that the TDC is a set of knowledge, skills and attitudes necessary for a teacher to make effective use of ICT from its different aspects (technological, informational, multimedia, communicative, collaborative and ethical), assuming pedagogical-didactic criteria for an effective integration of ICT in their educational practice and, in general, in any formal or non-formal situation. In this regard, Castañeda et al. (2018) state that the TDC must be holistic, situated, systemic, trainable and in constant development and, in addition, susceptible to integrate the skills, attitudes and knowledge that teachers require to support the learning of their students as active participants in a digital world (Domingo et al., 2020).

It is worth asking, once the meaning of the TDC has been delimited, whether university institutions currently integrate digital competence in their academic performance. In this context, there are various models and frameworks adopted by some countries that indicate the digital competencies in which teachers should be trained. Thus, the "European Framework for Digital Competence of Teachers: DigCompEdu" is articulated around six differentiated competency areas that teachers must possess to promote effective, inclusive and innovative learning strategies, using digital tools (Caena \& Redecker, 2019; Lu et al., 2021). On the other hand, the International Society for Technology in Education (ISTE) proposes the "Information and Communication 
Technology Standards for Teachers" (NETS-T). Another relevant project is the one developed by UNESCO on ICT Competencies for Teachers (UNESCO, 2008, 2019). In Spain we also have the "Common Framework of Digital Competence for Teachers" developed by the National Institute of Educational Technology and Teacher Training (INTEF, 2017), which is based on the digital competence model DigCompEdu developed by the EU.

However, most of these models and frameworks at national and international level focus on the pre-university level for different reasons. Among them is that accreditation systems measuring the quality of teaching value research more than didactic skills, which has led to the existing literature at the university level to focus more on student learning than on teacher instruction (Esteve et al., 2020). Despite this reality, there is now a growing interest, through different organizations and higher institutions, in knowing the state of digital competencies of university institutions and developing, based on this, training tools to improve them. The COVID-19 outbreak has even encouraged teachers to change their educational practice quickly and urgently in order to guarantee learning continuity for distance students. During this period, the pandemic showed that many teachers were virtually replicating face-to-face lessons, thus losing additional possibilities offered by technology for carrying out virtual activities and working with different types of resources (Cabero, 2020; Casado-Aranda et al., 2021; Usher et al., 2021). Along this line, the study by Trust and Whalen (2020) critically revealed that teachers felt overwhelmed and unprepared to use online or remote teaching strategies and methods and they found it challenging to adapt their pedagogy to problematics such as students' unreliable Internet access, changing personal needs, and unclear or shifting educational or governmental directives.

This exponential growth of problems, models and gaps in the competencies of university teachers calls for an assessment of the emerging research themes and subthemes on digital competences with an emphasis on theoretical models, pedagogical practices and applications. This research specifically analyzes (1) the latest research on the digital competence of university teachers in the international context, (2) and what are the main thematic lines that guide the different studies carried out in this area in order to delve into the training needs of teachers in the digital era. More particularly, the current analysis, therefore, aims to develop a systematic review to answer the following research questions related to TDC at university:

RQ1 What has been the growth of publications indexed in Web of Science (WoS) and Scopus databases between 1999 and May 2021?

RQ2 What are the main journals, authors and publications worth considering in future studies on the topic?

RQ3 What are the key emerging research themes and sub-themes on digital competences in higher education? On the one hand, RQ1 and RQ2 are key to academics who wish to publish papers and understand the digital teaching competences. On the other hand, RQ3 aims to provide insightful novel contributions regarding the identification of research clusters by means of a co-citation analysis. 


\section{Methodology}

The current study carried out consultations on 10 May 2021 on the WoS and Scopus databases about teachers' digital competence in tertiary/higher education. The query consultation in the WoS was as follows:

$\mathrm{AB}=$ ("University teacher" OR "University professor" OR "higher education") AND LANGUAGE: (English) AND DOCUMENT TYPES: (Article OR Review) AND $\mathrm{AB}=($ "digital competence" OR "online competence" OR "digital literacy") AND LANGUAGE: (English) AND DOCUMENT TYPES: (Article OR Review).

In Scopus, the search was the following one:

TITLE-ABS-KEY ("digital competence" OR "online competence" OR "digital literacy") AND TITLE-ABS-KEY ("University teacher" OR "University professor" OR "higher education") AND PUBYEAR> 1999 AND (LIMIT-TO (DOCTYPE,"ar") OR LIMIT-TO (DOCTYPE,"re") AND (LIMIT-TO (LANGUAGE,"English").

The starting search revealed over 343 articles in English, 152 of which were duplicates and therefore, were eliminated from further analysis. We then obtained 191 papers published between January 2000 and May 2021. The search was then focused and only those articles that specifically aligned with the research objectives on components of digital competence, ICT resources and educational projects and level of teachers' digital competences were selected. After this filtering, 56 articles were the basis for the bibliometric analysis.

In the analysis, we used the SciMAT open-source software (Cobo et al., 2011), which constitutes a useful tool for exploring the theoretical background of a given branch. Considering the output derived from the previous queries, the SciMAT software (i) classified the 56 manuscripts by publication date, citations, and journal titles and (ii) implemented a co-word search to clarify the most relevant topics associated with TDC in higher education. This co-word analysis constitutes a content analysis tool that uses patterns of co-occurrence of several items (such as words or nouns) within a collection of manuscripts aiming to recognize the links between ideas within the subject topics in the corpora. In this case, the co-word phase used text-mining tools for the titles, abstracts, and keywords, leading to the development of a strategic diagram highlighting the relative relevance of the topics associated with the competences of higher education teachers. This strategic diagram represents a graph implemented with the SciMAT software that highlights major topics based on their density (a measure of theme development) and centrality (a measure of the relevance of a theme) (See Fig. 1). The joint of low and high intensities of density and centrality facilitates the establishment of four quadrants:

Fig. 1 Strategic diagram

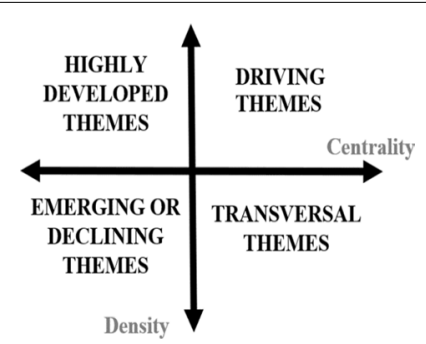


driving themes (strong centrality and high density), highly developed topics (low centrality and high density), emerging/declining issues (low centrality and density), and cross-sectional topics (high centrality and low density) (Cobo et al., 2011).

\section{Results}

\section{Scientific performance}

The results of the bibliometric analysis as extracted by the Scimat tool (Cobo et al., 2011) revealed a corpus of 56 peer-reviewed publications exploring the teachers' competences in higher education environments. We particularly identified 69\% through Scopus and $31 \%$ through WoS. It is worth noting that $54 \%$ of the Scopus publications and $60 \%$ of the WoS publications are open access. As can be seen in Fig. 2, there have been three main moments in which progress has been made in the study of university teachers' competences: 2012, 2014 and 2017. These three moments show an evident growth in publications, the most significant being 2017, which, as can be seen in Fig. 2, shows a growing trend today. It is no coincidence that this moment coincides with the publication of the European Framework for Teachers' Digital Competence (Redecker \& Punie, 2017), which turns out to be an essential document in TDC.

The assessment of the current digital competencles of university teachers has been addressed mainly in specialized journals such as Sustainability (3 papers), Education and Information Technologies (2 papers), Research in Learning Technology (2 papers), Espacios (2 papers), Journal of New Approaches in Educational Research (2 papers), The International Journal of Educational Technology in Higher Education (2 papers) or International Review of Research in Open and Distance Learning (2 papers). The academics with the highest amount of contributions in this matter are primarily from Spanish (Guillén Gámez, Margoya Fernández or Barroso-Osuna) and Portuguese (Dias Trindade or Gomes Ferreira) universities. Table 1 shows the most cited articles within the sample.

\section{Content analysis}

The content analysis of the keywords implemented with Scimat revealed a total of 165 major themes, as follows: B-learning, UAUT, surveys, COVID-19, models, social media, teacher training, digital competences, MOOCs, ICT, blogs, WEB 2.0, Athena, online



Fig. 2 Evolution of research on TDC from 2000 to 2021 
Table 1 Top publications by number of citations on educational competences and higher education

\begin{tabular}{|c|c|c|}
\hline Publications & DOI & Total citations \\
\hline $\begin{array}{l}\text { Factors affecting faculty use of learning technologies: Implica- } \\
\text { tions for models of technology adoption (Journal of Comput- } \\
\text { ing in Higher Education) }\end{array}$ & 10.1007/s12528-013-9066-6 & 101 \\
\hline $\begin{array}{l}\text { Openness and praxis: Exploring the use of open educational } \\
\text { practices in higher education (The International Review of } \\
\text { Research in Open and Distributed Learning) }\end{array}$ & 10.19173/irrodl.v18i5.3096 & 71 \\
\hline $\begin{array}{l}\text { Digital transformation in German higher education: student } \\
\text { and teacher perceptions and usage of digital media (Interna- } \\
\text { tional Journal of Educational Technology in Higher Education) }\end{array}$ & $10.1186 / s 41239-018-0130-1$ & 38 \\
\hline $\begin{array}{l}\text { Reclaiming literacies: Competing textual practices in a digital } \\
\text { higher education (Teaching in Higher Education) }\end{array}$ & $10.1080 / 13562517.2012 .756465$ & 28 \\
\hline
\end{tabular}

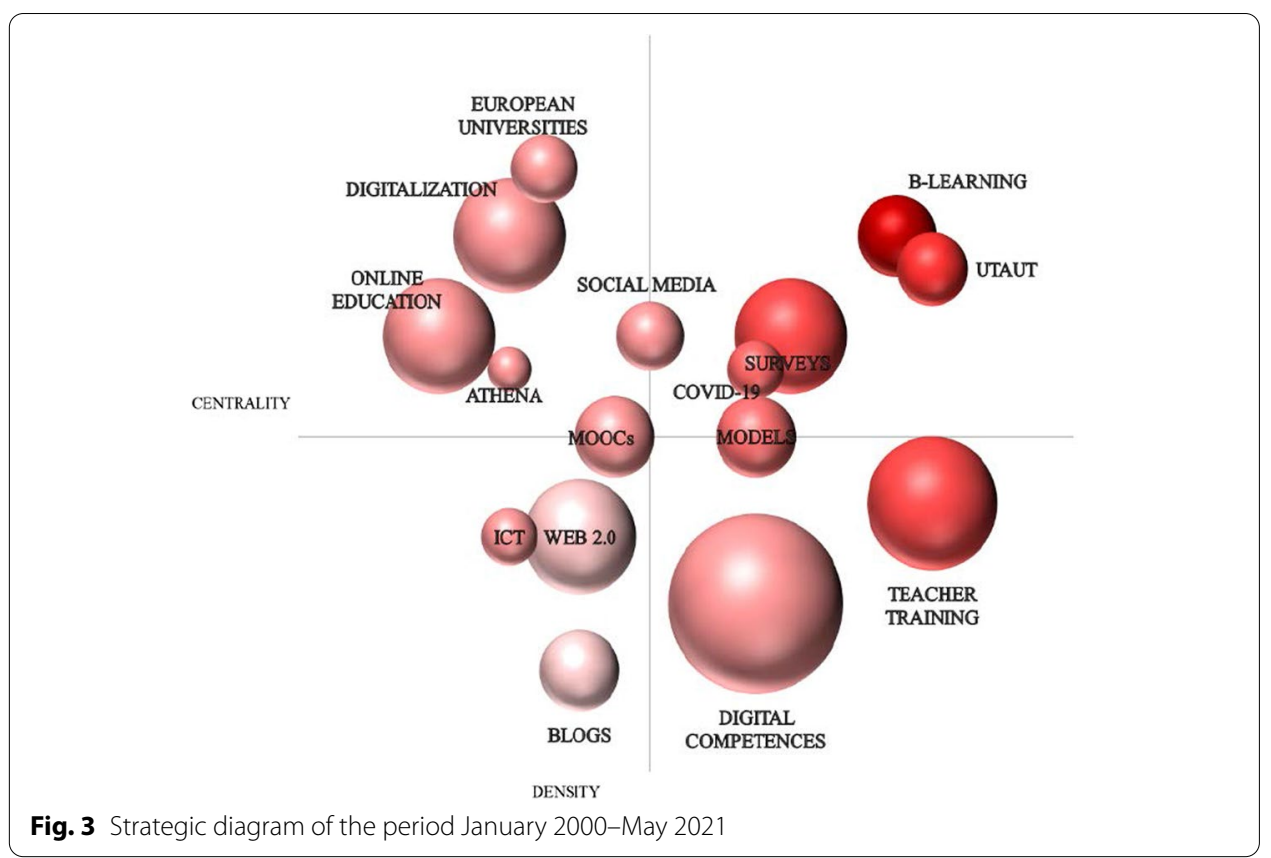

education, digitalization and European Universities. The strategic diagram in Fig. 3 highlights the combination of topics of teachers' competences in the higher education context. The number of papers including each keyword is proportional to the volume of each sphere. This content analysis also aims to shed light on the link between the keywords and the most recurrent subtopics by means of the so-called thematic networks. More specifically, "the size of the spheres for a thematic network is proportional to the number of articles corresponding to each keyword, whereas the width of the link between two spheres $i$ and $j$ is proportional to the eij equivalence index" (Casado-Aranda et al., 2020, p. 1). The following section describes the strategic diagram and the main thematic networks derived from the content analysis.

As we can see in Fig. 4, the data analysis corroborates that B-learning and social networks are two driving forces, i.e. ICT resources with potential growth in university 

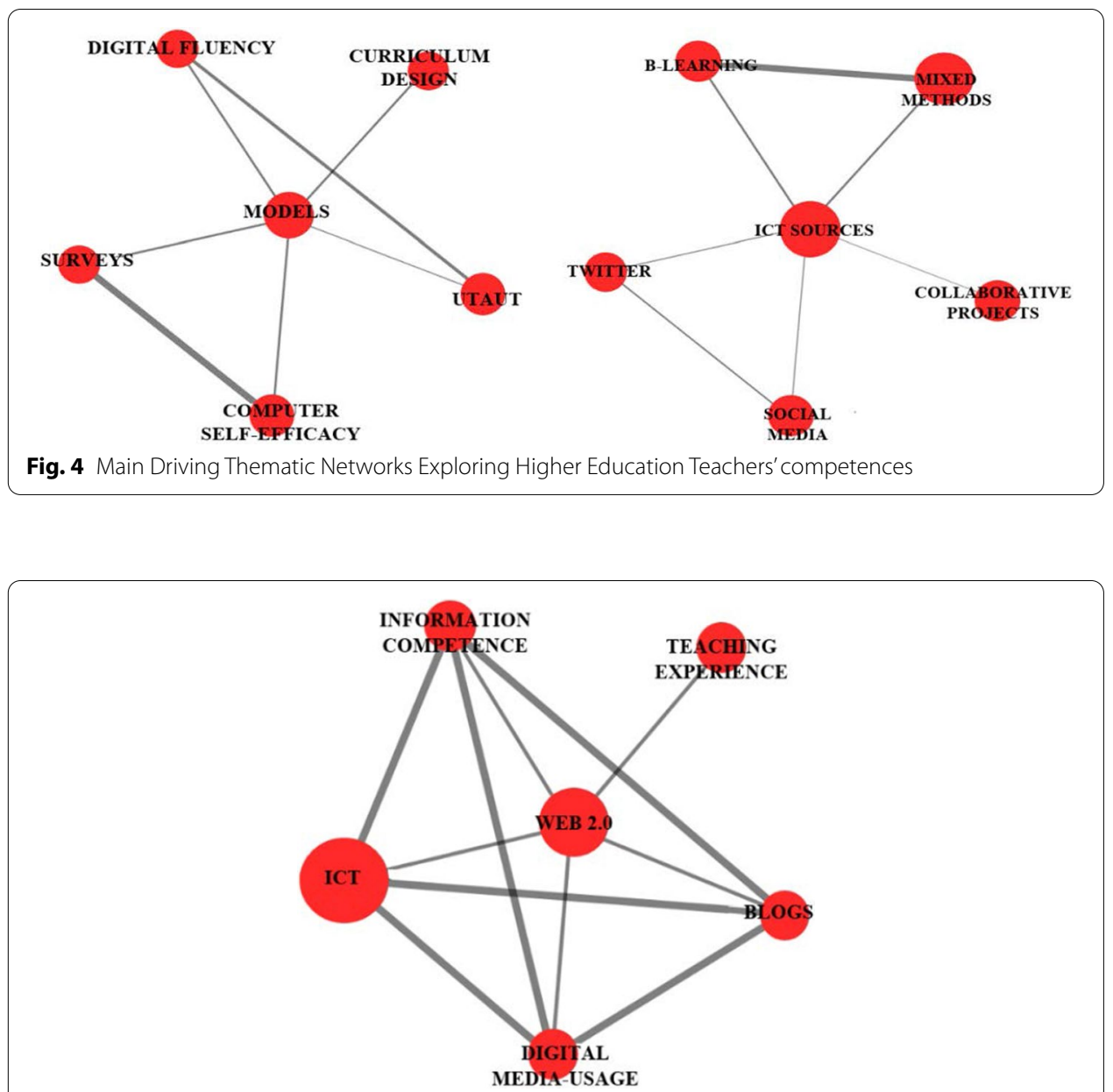

Fig. 5 Emerging and declining thematic networks in university TDC

education. In addition, some models and frameworks for the assessment of teaching digital competence, such as UTAUT, and other surveys such as DigCompEdu CheckIn are proving to be crucial for the self-assessment of teaching digital competence and digital fluency.

As can be seen in Fig. 5, Web 2.0, especially social networks and MOOCs, are resources that, although they have been developed and implemented in educational practice for some time, are now emerging and gaining special importance in teaching experiences as they favor digital competence. In fact, they are resources that teachers tend to use frequently nowadays. However, blogs seem to be dropping. Although they are still of key relevance for university on an institutional context as a highly developed resource, they might be losing momentum today and giving way to new ICT resources.

Next, we analyze the recurrent and cross-cutting themes (see Fig. 6). As we can see in Figure A (which corresponds to the upper left sector of Fig. 3), digitization, online education, the Athena project and European universities are very relevant themes. In particular, the Athena project has analyzed the development and consequences of the Athena project, which aims to contribute to the development, reform and modernization 


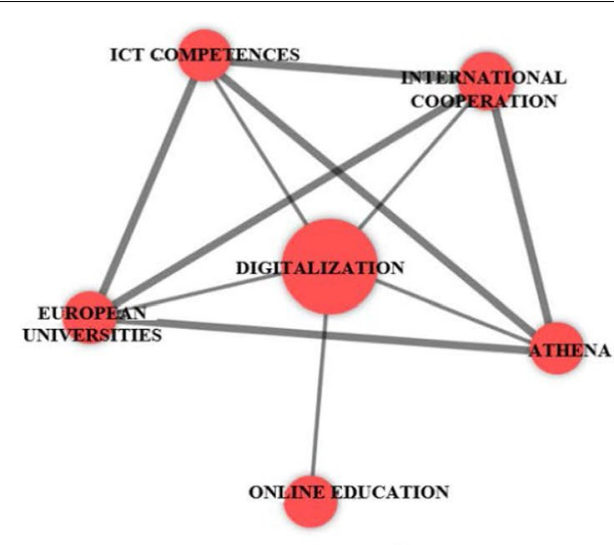

A

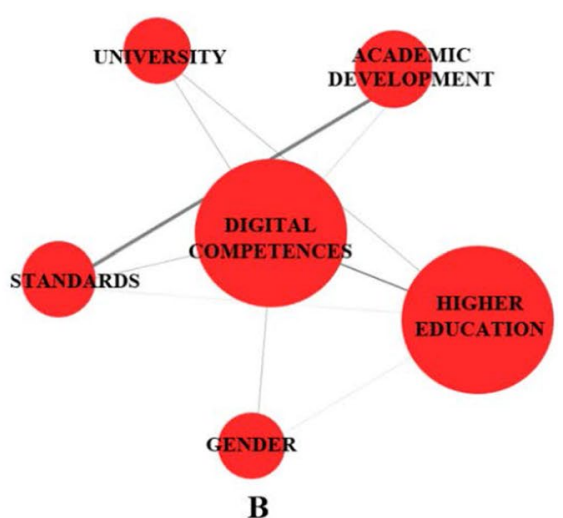

B

Fig. 6 Thematic networks showing $\mathbf{A}$ highly more relevant topics and $\mathbf{B}$ cross-cutting topics

of higher education systems in Europe, as well as to the implementation of online education at all educational levels.

Finally, as we can see in Figure B (which corresponds to the lower right sector of Fig. 3), digital competencies in higher education and the study of gender as an influential variable are topics that have acquired significant relevance in the period analyzed, but which are transversal to all the research carried out.

\section{Emerging lines of research}

The content of the 56 articles selected is organized into three main topics: a) frameworks and models for assessing TDC, b) level of digital competence of university teachers, and c) educational proposals and projects that have been applied to develop TDC. The following is a synthesis of the main issues addressed in these three research lines, which are closely linked to the issues identified and described in the previous sections as a result of the statistical analyses carried out.

(a) In order to assess and determine the level of digital competence of university teachers, it is necessary to rely on frameworks and theoretical reference models that identify the dimensions and components of digital competence. An example of this is Bennett's (2014) research which explores how Sharpe and Beetham's digital literacy framework can be applied to university teachers' digital literacy practices. As a result, a revised form of this model is developed and applied to teachers. This model is called "The Digital Practitioner Framework" (DPF) and represents the notion of "digital practitioner" proposed by Ecclesfield et al. (2012). The DPF is particularly proposed as a way of modeling the characteristics that are likely to be found in lecturers who adopt technology in their teaching and learning practices. This framework represents the attributes, practices and skills and access of a 'digital practitioner. This notion particularly describes lecturers who are confident in their use of TEL, have a self-managed approach to adoption, willingness to experiment and to invest time in exploring the tools and how they might be applied to teaching and learning practice.

The study by Mirriahi et al. (2015) is also worth mentioning as it presents a blended learning framework with indicators to measure, on the one hand, the capacity of 
teachers in these environments; and on the other, the standards that define the quality of their practice, all of them supporting the evaluation and advancement of blended learning in higher education. For their part, Blayone et al. (2017) have selected the "General Technology Competency and Use" (GTCU) framework to conceptualize and measure the digital competencies of university teachers. This model identifies three dimensions of digital competence: epistemological, informational and social. Notwithstanding, DiazTrindade and Ferreira (2020) present the preliminary results of a pilot study that confirms the relevance of DigCompEdu CheckIn as a self-assessment model to determine the level of TDC.

Finally, Nikou and Aavakare (2021) develop in their study a conceptual model to examine the impact of information literacy and digital literacy on university staff. To do so, they adapt the integrated model of the "Unified Theory of Acceptance and Use of Technology" (UTAUT) by including digital literacy and information literacy as additional predictors of intention to use digital technologies. The results indicate that information literacy has a direct and significant impact on intention to use the above mentioned technologies.

(b) Secondly, and in accordance with the categories outlined above, the results of empirical studies on the level of TDC in higher education have been analyzed. Although they have been collected through different tools and strategies, most of them are based on teachers' self-perception. In general, the selected sources argue that teachers possess moderate levels of digital competence (Guillén \& Mayorga, 2020; Montoro et al., 2015; Romero et al., 2019). Among these skills are the ability to solve problems using ICT, work with a network of contacts and use 2.0 tools to evaluate. Besides, Blayone et al. (2017) add technical competence (creating and editing documents and managing online accounts, etc.), social competence (communicating by email, sending and receiving messages, and participating in social networks, etc.), informational competence (finding and using articles, news and videos, etc.) and epistemological competence (time management, organization and presentation of complex information, etc.), the last one being with the poorer results.

Following this same line, Dias-Trindade et al. (2020) show in their study that the competencies "instruction", "analyzing evidence" and "well-being" of the DigCompEdu model are the weakest, and that teachers perceive to have more competence in "data management". The study by Romero Contreras and Pérez (2019) argue that the general level of digital competence of teachers does not exceed the medium-low level if the following aspects are considered. First, language, which is conceived as understanding various media linguistic codes, as well as the teachers' skills to interpret and evaluate representation resources, and the analysis and evaluation of messages. Second, technology or the ability to manage multimedia and multimodal communication tools, adapt technological tools to their communicative objectives, and produce and control sounds and images. Interaction also stands out as a vital component of digital competence as it shows an active critical attitude towards the media, and the ability to perform collaborative work and interact with individuals or groups in different media environments. To end with, the authors also stress production and dissemination, ideology (i.e., the ability to understand how the media construct realities, to assess the reliability of information sources and to search, organize, contrast, prioritize and synthesize information) and aesthetics 
(being aware of the aesthetic tools that the media use to exert influence, generate emotions and convey a message to make it more credible and attractive) as key competences of teachers in higher education.

The research also explores the ability of teachers to help their students develop digital competencies. In this regard Sales et al. (2020) point out that teachers doubt of their ability to train students in digital competencies, and attribute the difficulty in achieving and promoting such learning to the lack of coordination among faculty or the way in which the EHEA has been implemented in universities. In addition to the results focused on the assessment of digital competencies of university teachers, some research also examined aspects such as frequency of use or perceived usefulness. In this regard, Bond et al. (2018) show that teachers frequently use the university platform, especially for management tasks.

Following the same line, Podorova et al. (2019) state that teachers use technologies regularly, especially their institution's virtual platform to give feedback and engage student mobile technologies being the least used. In addition, they recognize the importance of using digital tools, above all, to collaborate and communicate, and to a lesser extent to evaluate and participate in social networks. They also point out that they learn in a self-taught manner and that when they need help, they turn to the Internet or consult their peers informally. This result coincides with the study by Montoro et al. (2015) who point out that teachers prefer self-learning and through trial and error.

Guillén et al. (2021) state that teachers use ICT resources, with a higher use in the teaching and research dimensions compared to the evaluation dimension. Also, Amhag et al. (2019) point out that teachers do not use digital tools for educational purposes and need extensive pedagogical support to create digital quality teaching.

Likewise, some authors analyze the factors that influence the development of digital competence of higher education teachers. The variables that have been most explored are those related to the individual characteristics of teachers. Thus, Guillén and Mayorga (2019) find differences according to gender, years of experience and professional experience, and found that these variables negatively predicted the acquisition of TDC. In contrast, research and innovation projects are found to have a positive impact.

For their part, Basantes et al. (2020) show that the level of digital competencies is independent of gender but does depend on age. Following this same line, Cabero et al. (2021) find that there are no significant differences between gender and teachers' digital competencies. The results. Therefore, show that both teachers aged between 30 and 49 years and teachers with experience between 4 and 14 years show greater digital competence.

Regarding the external difficulties that teachers may encounter when integrating digital competencies in their professional work, a recent study on teaching performance during the COVID19 shows that the greatest difficulties for teachers during the pandemic were deficiencies in their training in digital skills, which made them perceive a greater workload during the lockdown together with different negative emotions (Portillo et al., 2020).

(c) Finally, and in accordance with the literature reviewed, the results of studies that provide specific classroom educational initiatives, innovation projects or even European institutional projects that can favor the development of teaching digital competence have been analyzed. 
Specifically, the study by Fadli et al. (2020) addresses the use of MOOCs as a tool for the transition from face-to-face teaching to a long-distance teaching model. In turn, Gleason and Manca (2020) conduct a case study on the use of Twitter highlighting the benefits of this tool as an enabler of participation, professional development and digital literacy.

There are also didactic experiences with blogs in higher education oriented to the development of digital, linguistic and interpersonal competencies in which improvements are observed after their implementation (Neira-Piñeiro et al., 2013). Another study indicates that the use of video has a positive impact on the achievement of digital competence. The findings reveal that informational competence improves when videos are used as learning objects, since this type of practice involves an increase in the search, management and use of digital data (García-Esteban, 2017).

In addition to these investigations, several researchers analyzed the results of the implementation of innovation projects in the university context. We highlight the work of Mahapatra (2020) that analyzes the impact of a training program in digital technologies, the results suggest a positive impact on teaching practice as well as the detection of important factors in the TDC such as motivation, administrative support or students' response to the use of technologies. In the study by Ruiz-Cabezas et al. (2020), the results show the teachers' interest in understanding and integrating digital competence in teaching and generating a culture of professional development, all this through the analysis of educational practice and the use of mini-videos. Following this same line, Marzal et al. (2019) describe the implementation of an innovation project at their university and show its instructional design, the didactic materials used, the didactic activities carried out, and the evaluation.

Finally, some researchers describe projects of institutions coming from different European countries that enhance an improvement of the TDC. For example, we highlight the study by Quadrado et al. (2021) who present the Athena project, which focuses on new EU grant programs that enhance the increase of digital literacy in higher education, the development of cooperation and overcoming challenges during the coronavirus pandemic. This initiative may empower a new European university and support an international project aimed at certifying professional educators. It is also interesting to note Handley's (2018) study that presents an overview of recent initiatives around digital skills and literacies in UK higher education, highlighting the main projects of several national organizations and the impact these have had on institutional programs to improve digital skills and literacies.

\section{Discussion and conclusions}

As we have seen throughout this paper, in the last decade there has been a notable and exponential increase in the number of publications on TDC especially in recent years. This literature review complements others conducted previously, such as RodríguezGarcía, Aznar Díaz, et al. (2019), Rodríguez-García, Raso Sánchez, et al. (2019), (2019c) and Esteve et al. (2020); which indicate that the study of digital competence has become, at present, a powerful line of research given the need to train highly digitally skilled teachers. 
Our findings highlight that the TDC is one of the challenges that university teachers must face. It is to be expected that scientific production, therefore, will continue to increase for two fundamental reasons. One of these is precisely the need for teachers to delve deeper into its meaning, significance and scope; the other is the impetus given to the digitization of education by the COVID-19 health crisis, which seems to have been the definitive springboard for the inclusion of digital competencies in the university context. The effort made by higher education institutions towards the virtual development of teaching, as a consequence of the pandemic, has led to a review of educational practices to adapt teaching to a digital environment (Sales et al., 2020).

In addition, the review has shown that, despite having the resources to do so, university on an institutional context still have a long way to go in terms of their digital competencies. In the literature we find a predominance of research that focuses on analyzing the self-assessment and reflection that teachers carry out on their digital competencies, especially through questionnaires or surveys. In fact, statistical analyses confirm these data a low or medium-low digital competence. Among these skills are the ability to solve problems using ICT, work with a network of contacts and use 2.0 tools to evaluate. Teachers, in general, recognize the absence of some competencies, especially linked to the evaluation of educational practice, so they demand pedagogical support to create quality teaching and advocate the incorporation of technologies in the actual work methodology of all subjects, not in a segregated way (Amhag et al., 2019; Blayone et al., 2017; Guillén \& Mayorga, 2020; Montoro et al., 2015; Romero et al., 2019). These results are coincident with the study by Demeshkant et al. (2020) who point out that Polish academic teachers have a medium level of digital competences both in Pedagogical as well as Technological Knowledge; and that by Santos et al. (2021) who proved that Portuguese higher education teachers have a low level of digital competence in the area of assessment in the DigCompEdu model. The authors claim that this is quite worrying since assessment issues are vital to monitor students' progress, enable effective feedback and allow educators to assess and adapt their learning strategies.

Nevertheless, and as a positive aspect, the selected articles also show a good predisposition of teachers and a favorable attitude towards competency development; proof of this is the number of articles that try to articulate frameworks and models to enhance competency development, as well as the innovation proposals or educational projects that have been implemented. "The Digital Practitioner's Framework" can prove extremely useful to identify which are the main features and competences that higher education teachers need in order to welcome technologies in their educational practices, and reinforce their development training. There is still a long way to go, but the increasingly abundant literature on these issues shows the interest and relevance of TDC. Another indicator that the digital competence of university teachers is in full swing is the work conducted by the European Union with the self-reflection tool for teachers called "DigCompEdu Check-In", whose fundamental objectives are to enable educators to better understand the DigCompEdu framework, and provide them with a way to self-assess their strengths and weaknesses in the use of digital technologies in education (Cabero \& Palacios, 2020; Dias-Trindade et al., 2020).

There is no doubt, as indicated at the beginning of this paper, that since the beginning of the millennium there has been a real digital revolution, and higher education must 
be prepared to respond to the needs of this digital society in which we are immersed, as well as be able to anticipate the needs of the coming society. This interpellation that implies an adaptation to social changes on the part of higher education extends to the university teaching staff who, as an inherent part of the university, must face and respond to the social challenges, to the changes that have occurred and to what is yet to come. The teaching staff is aware that this challenge is part of their work; as Triadó (2020) states "we never finish learning, (...) students change, knowledge advances, and it is always necessary to be up to date. A good teacher, like any professional who wants to stand out, cannot stop continuous training" (p. 12).

Thus, a central pillar in the professional development of university teachers is continuous training, the search for the development of teaching competencies in all its dimensions. This is perhaps the great challenge for university teachers in the twenty-first century: not to become comfortable, to continue learning and to continue researching.

The first step to understand the training needs of teachers in the digital era is to identify the starting point. The competency development of each teacher depends on multiple factors, as we have seen in this literature review. There are huge differences in the TDC between different groups according to various variables, which highlights the need to structure more personalized training plans in this area (Basilotta et al., 2020; Cabero et al., 2021). Thus, the training offer must be varied and must respond to diverse needs.

In this regard, many articles analyzed point to the need for teachers to increase their level of digital competence through specific training, especially regarding the pedagogical use of technology, particularly more practical and experiential training (DiasTrindade \& Ferreira, 2020). Thus, although teacher training programs represent good ways to stimulate teachers to develop digital competence for pedagogical purposes, this aspect seems to be poorly integrated within the actual programs (Tomte et al., 2015). It is, therefore, determinant that there is greater coherence between initial and continuing teacher training. The training and professional development of individual teachers should be seen as an ongoing task, and should be organized and funded accordingly.

Also of interest in the current context is the growing prominence of the creation of collaborative teacher networks or learning communities. In fact, the literature analyzed points out that teachers often learn in a self-taught manner, preferring self-learning and trial and error, and when they need help, they turn to the Internet or consult their peers informally (Montoro et al., 2015; Podorova et al., 2019). From this point of view, online help and advice is positively valued because it can allow teachers to share knowledge and information, detect professional problems and seek alternatives, as well as motivate them to make changes and improve educational practice.

An extremely important issue would be to recognize, accredit and certify these competencies. The implementation of such processes would imply having valid and transparent instruments not only for their evaluation, but also for recognizing and accrediting the formal, non-formal and informal learning of teachers. With this, we would be overcoming one of the most important solvable challenges pointed out by the 2014 Horizon Report, the lack of reward in teaching (Tejada \& Pozos, 2018).

Finally, and as with all research, this work has its limitations. Taking into account the increasing importance of this topic, it would be convenient to perform more exhaustive analyses of the statistical results achieved, analyzing the relationship between keywords 
and their implication in the identified axes and thematic lines. An additional challenge would be to incorporate terms in Spanish in the search, given that we have identified that there is a large literature on this topic in Spain and South America. These limitations may provide an impetus for future research, with the inclusion of new terms in the review and the expansion of the number of researchers. Another important line of future work is to delve deeper into the assessment of teachers' digital competencies, given that this issue has a strong predominance in the literature analyzed.

Acknowledgements

Not applicable.

Authors' contributions

VB-G-P and MM led the study and supervised the data analysis, L-AC-A and AO conducted the data collection and completed the analysis. All authors read and approved the final manuscript.

\section{Funding}

This article received support from the Teaching Innovation Project PIBD Basic II of the UGR (Grant No. 21-71): FlippedClassroom and Work-integrated Learning as Active Methodologies for Teaching Marketing in English and from the Innovation Project for The Improvement of Pre-service Teacher Training in Online Contexts (\#BetterTeachers) (Grant No. ID-UDIMA-2020-02)

\section{Availability of data and material}

The data that support the findings of this study are available on request from the corresponding author.

\section{Declarations}

Competing interest

Not applicable.

\section{Author details}

${ }^{1}$ Facultad de Ciencias de la Salud y la Educación, Departamento de Educación, Universidad a Distancia de Madrid, Vía de Servicio A-6, 15, Collado Villalba, 28400 Madrid, Spain. ${ }^{2}$ Faculty of Business and Management, Marketing and Market Research Department, University of Granada, Granada, Spain.

Received: 20 July 2021 Accepted: 14 December 2021

Published online: 10 February 2022

\section{References}

Amhag, L., Hellstrom, L., \& Stigmar, M. (2019). Teacher educators' use of digital tools and needs for digital competence in higher education. Journal of Digital Learning in Teacher Education, 35(4), 203-220. https://doi.org/10.1080/21532974. 2019.1646169

Basantes, A., Cabezas, M., \& Casillas, S. (2020). Digital competences relationship between gender and generation of university professors. International Journal on Advanced Science Engineering Information Technology, 10(1), 205-211.

Basilotta, V., García-Valcárcel, A., Casillas, S., \& Cabezas, M. (2020). Evaluación de competencias informacionales en escolares y estudio de algunas variables influyentes. Revista Complutense De Educación, 31(4), 517-528. https://doi.org/ $10.5209 /$ rced.65835

Bennett, L. (2014). Learning from the early adopters: Developing the digital practitioner. Research in Learning Technology, 22, 1-13. https://doi.org/10.3402/rlt.v22.21453

Blayone, T., Mykhailenko, O., VanOostveen, R., Grebeshkov, O., Hrebeshkova, O., \& Vostryakov, O. (2017). Surveying digital competencies of university students and professors in Ukraine for fully online collaborative learning. Technology, Pedagogy and Education, 27(3), 279-296. https://doi.org/10.1080/1475939X.2017.1391871

Bond, M., Marín, V. I., Dolch, C., Bedenlier, S., \& Zawachi-Richter, O. (2018). Digital transformation in German higher education: Student and teacher perceptions and usage of digital media. International Journal of Educational Technology in Higher Education, 15(48), 1-20. https://doi.org/10.1186/s41239-018-0130-1

Cabero, J. (2020). Aprendiendo del tiempo de la COVID-19. Revista Electrónica Educare, 24(Suppl. 1), 4-6. https://doi.org/ 10.15359/ree.24-s.2

Cabero, J., Barroso, J., \& Palacios, A. (2021). Digital competences of educators in Health Sciences: Their relationship with some variables. Educación Médica, 22(2), 94-98. https://doi.org/10.1016/j.edumed.2020.11.014

Cabero, J., Barroso, J., Palacios, A., \& Llorente, C. (2020). Marcos de Competencias Digitales para docentes universitarios: Su evaluación a través del coeficiente competencia experta. Revista Electrónica Interuniversitaria De Formación Del Profesorado, 23(2), 1-18. https://doi.org/10.6018/reifop.413601

Cabero, J., \& Palacios, A. (2020). Marco Europeo de Competencia Digital Docente «DigCompEdu» y cuestionario «DigCompEdu Check-In». EDMETIC, Revista De Educación Mediática y TIC, 9(1), 213-234. https://doi.org/10.21071/edmet ic.v9i1.12462 
Caena, F., \& Redecker, C. (2019). Aligning teacher competence frameworks to 21st century challenges: The case for the European Digital Competence. Framework for Educators (DigCompEdu). European Journal of Education, 54(3), 1-14. https://doi.org/10.1111/ejed.12345

Casado-Aranda, L.-A., Sánchez-Fernández, J., Montoro-Ríos, F. J., \& Horcajadas, M. I. A. (2021). Evaluation of the work-integrated learning methodology: Teaching marketing through practitioner experience in the classroom. Mathematics, 9(17), 2164. https://doi.org/10.3390/math9172164

Casado-Aranda, L.-A., Sánchez-Fernández, J., \&Viedma-del-Jesús, M. I. (2020). Analysis of the scientific production of the effect of COVID-19 on the environment: A bibliometric study. Environmental Research, 193, 1-12. https://doi.org/10. 1016/j.envres.2020.110416

Castañeda, L., Esteve, F., \& Adell, J. (2018). ¿Por qué es necesario repensar la competencia docente para el mundo digital? RED. Revista De Educación a Distancia, 56, 2-20. https://doi.org/10.6018/red/56/6

Cobo, M. J., López-Herrera, A. G., Herrera-Viedma, E., \& Herrera, F. (2011). An approach for detecting, quantifying, and visualizing the evolution of a research field: A practical application to the Fuzzy Sets Theory field. Journal of Informetrics, 5(1), 146-166.

Consejo de la Unión Europea (2018). Recomendación del Consejo, de 22 de mayo de 2018, relativa a las competencias clave para el aprendizaje permanente. Retrieved from https://eur-lex.europa.eu/legal-content/ES/TXT/PDF/?uri= CELEX:32018H0604(01)\&from=SV.

Demeshkant, N., Potyrala, K. \& Tomczyk, L. (2020). Levels of academic teachers digital competence: Polish case-study. In So, H. J. et al. (Eds.) (2020). Proceedings of the 28th International Conference on Computers in Education (pp. 591-601). Asia-Pacific Society for Computers in Education.

Dias-Trindade, S., \& Ferreira, A. (2020). Digital teaching skills: DigCompEdu Checkln as an evolution process from literacy to digital fluency. Icono 14. Revista De Comunicación y Tecnologías Emergentes, 18(2), 162-187. https://doi.org/10. 7195/ri14.v18i1.1519

Dias-Trindade, S., Moreira, J. A., \& Ferreira, A. (2020). Assessment of university teachers on their digital competences. Qwerty, 15(1), 50-69. https://doi.org/10.30557/QW000025

Domingo, M., Bosco, A., Carrasco, S., \& Sánchez, J. A. (2020). Fomentando la competencia digital docente en la universidad: Percepción de estudiantes y docentes. Revista De Investigación Educativa, 38(1), 167-782. https://doi.org/10 6018/rie.34055

Durán, M. (2019). Competencia Digital del Profesorado Universitario: Diseño y Validación de un Instrumento para la Certifcación. Murcia. Universidad de Murcia-Escuela Internacional de Doctorado.

Ecclesfield, N., Rebbeck, G., \& Garnett, F. (2012). The case of the curious and the confident the untold story of changing teacher attitudes to e-learning and "'technology in action"' in the FE sector. Compass: the Journal of Learning and Teaching at the University of Greenwich, 5, 1-57.

Esteve, F., Llopis, M. A., \& Adell, J. (2020). Digital teaching competence of university teachers: A systematic review of the literature. IEEE Revista Iberoamericana De Tecnologías Del Aprendizaje, 15(4), 399-406. https://doi.org/10.1109/RITA. 2020.3033225

Fadli, M., Maharani, D. P., \& Liemanto, A. (2020). A new paradigm of regulation for massive open online courses (MOOCs) in higher education in Indonesia: From disruptive innovation to sustaining innovation. International Journal of Innovation, Creativity and Change, 11(6), 442-457.

García-Esteban, S. (2017). Do video learning objects develop digital competence in teacher training? RAEL:Revista Electrónica De Lingüistica Aplicada, 6(1), 85-102.

Gleason, B., \& Manca, S. (2020). Curriculum and instruction: Pedagogical approaches to teaching and learning with Twitter in higher education". On the Horizon, 28(1), 1-8. https://doi.org/10.1108/OTH-03-2019-0014

Guillén, F. D., \& Mayorga, M. (2019). Prediction and explanation of factors that affect the digital competence of lecturers: A case study at Spanish University. The International Journal of Learning in Higher Education, 26(2), 107-117. https://doi. org/10.18848/2327-7955/CGP/v26i02/107-117

Guillén, F. D., \& Mayorga, M. (2020). Prediction of factors that affect the knowledge and use higher education professors from Spain make of ICT resources to teach, evaluate and research: A study with research methods in educational technology. Education Sciencies, 10(276), 1-12. https://doi.org/10.3390/educsci10100276

Guillén, F. D., \& Mayorga, M. a. (2021). Examining the use self-perceived by university teachers about ICT resources: Measurement and comparative analysis in a one-way ANOVA design. Contemporary Educational Technology, 13(1), 1-13. https://doi.org/10.30935/cedtech/8707

Handley, F. J. L. (2018). Developing digital skills and literacies in UK higher education: Recent developments and a case study of the digital literacies framework at the University of Brighton, UK. Publicaciones, 48(1), 97-109. https://doi. org/10.30827/publicaciones.v48i1.7327

INTEF. (2017). Common Digital Competence Framework for Teachers - September 2017. Ministry of Education, Culture and Sport.

Lu, L., Mirpuri, S., Rao, N., \& Law, N. (2021). Conceptualization and measurement of digital citizenship across disciplines. Educational Research Review, 33, 1-18. https://doi.org/10.1016/j.edurev.2021.100379

Mahapatra, S. (2020). Impact of digital technology training on English for science and technology teachers in India. RELC Journal, 51(1), 117-133. https://doi.org/10.1177/0033688220907401

Marzal, M. A., Cruz, E., \& Castro, F. (2019). A didactic innovation project in Higher Education through a Visual and Academic Literacy competence-based program. Education for Information, 35(3), 263-283. https://doi.org/10.3233/ EFI-190284

MINECO (2021). Plan Nacional de Competencias Digitales. Retrieved from https://portal.mineco.gob.es/RecursosArticulo/ mineco/ministerio/ficheros/210127_plan_nacional_de_competencias_digitales.pdf

Mirriahi, N., Alonzo, D., \& Fox, B. (2015). A blended learning framework for curriculum design and professional development. Research in Learning Technology, 23, 1-14. https://doi.org/10.3402/rlt.v23.28451

Montoro, M., Hinojo, F. J., \& Sánchez, F. (2015). A study on ICT training among faculty members of Spanish Faculties of Education. The New Educational Review, 42, 27-39. https://doi.org/10.15804/tner.2015.42.4.02 
Neira-Piñeiro, M. D., Villalustre, L., \& Del-Moral, E. (2013). didactic experiences with blogs in training teachers: Writing in digital media to develop professional competences. The International Journal of Technologies in Learning, 19(2), 51-64. https://doi.org/10.18848/2327-0144/CGP/v19i02/59007

Nikou, S., \& Aavakare, M. (2021). An assessment of the interplay between literacy and digital Technology in Higher Education. Education and Information Technologies. https://doi.org/10.1007/s10639-021-10451-0

Podorova, A., Irvine, S., Kilmister, M., Hewison, R., Janssen, A., Speziali, A., Balavijendran, L., Kek, M., \& McAlinden, M. (2019). An important, but neglected aspect of learning assistance in higher education: Exploring the digital learning capacity of academic language and learning practitioners. Journal of University Teaching \& Learning Practice, 16(4), 1-21.

Portillo, J., Garay, U., Tejada, E., \& Bilbao, N. (2020). Self-perception of the digital competence of educators during the COVID-19 pandemic: A cross-analysis of different educational stages. Sustainability, 12(23), 1-13. https://doi.org/10. 3390/su122310128

Quadrado, J. C., Pokholkov, P., \& Zaitseva, K. K. (2021). ATHENA: Contributing to development of higher education institutions for the digital age. Higher Education in Russia, 30(1), 125-131. https://doi.org/10.31992/ 0869-3617-2021-30-11-125-131

Redecker, C., \& Punie, Y. (Eds.). (2017). European framework for the digital competence of educators: DigCompEdu. Publications Office of the European Union.

Rodríguez-García, A. M., Aznar Díaz, l., Cáceres Reche, P., \& Gómez-García, G. (2019). Digital competence in higher education: Analysis of the impact of scientific production indexed in Scopus database. Revista Espacios, 40(21), 1-14.

Rodríguez-García, A. M., Raso Sánchez, F., \& Ruiz-Palmero, J. R. (2019). Competencia digital, educación superior y formación del profesorado: Un estudio de meta-análisis en la Web of Science. Pixel-Bit. Revista De Medios y Educación, 54, 65-81. https://doi.org/10.12795/pixelbit.2019.154.04

Romero-Rodríguez, L. M., Contreras-Pulido, P., \& Pérez-Rodríquez, M. A. (2019). Media competencies of university professors and students. Comparison of levels in Spain, Portugal, Brazil and Venezuela. Culture and Education, 31(2), 326-368. https://doi.org/10.1080/11356405.2019.1597564

Ruiz-Cabezas, A., Del Castañar, M., Pérez-Navío, E., \& Medina-Rivilla, A. (2020). University teachers'training: The Digital Competence. Pixel-Bit. Revista De Medios y Educación, 58, 181-215. https://doi.org/10.12795/pixelbit.74676

Sales, D., Cuevas-Cerveró, A., \& Gómez-Hernández, J. A. (2020). Perspectives on the information and digital competence of social sciences students and faculty before and during lockdown due to covid-19. Profesional De La Información, 29(4), 1-20. https://doi.org/10.3145/epi.2020.jul.23

Santos, C., Pedro, N., \& Mattar, J. (2021). Digital competence of higher education professors: Analysis of academic and institutional factors. Obra Digital, 21, 69-92. https://doi.org/10.25029/od.2021.311.21

Silva, J., Lázaro, J. L., Miranda, P., \& Canales, R. (2018). El desarrollo de la competencia digital docente durante la formación del profesorado. Revista De Ciencias Humanas y Sociales, 86, 423-449.

Tejada, J., \& Pozos, K. (2018). Nuevos escenarios y competencias digitales docentes: Hacia la profesionalización docente con TIC. Profesorado, Revista De Curriculum y Formación Del Profesorado, 22(1), 25-51.

Tomte, C., Enochsson, A. B., Buskqvist, U., \& Karstein, A. (2015). Educating online student teachers to master professional digital competence: The TPACK-framework goes online. Computers \& Education, 84, 26-35. https://doi.org/10.1016/j. compedu.2015.01.005

Triadó, X. M. (2020). Prólogo. In M. Turull (Coord.). Manual de Docencia Universitaria (pp. 11-21). Octaedro.

Trust, T., \& Whalen, J. (2020). Should teachers be trained in emergency remote teaching? Lessons learned from the COVID-19 pandemic. Journal of Technology and Teacher Education, 28(2), 189-199.

UNESCO. (2008). ICT Competency Standars for Teachers. UNESCO.

UNESCO. (2019). Marco de competencias de los docentes en materia de TIC. UNESCO.

Usher, M., Hershkovitz, A., \& Forkosh-Baruch, A. (2021). From data to actions: Instructors' reflections about learners' data in online emergency remote teaching. The British Journal of Educational Technology, 52(4), 1338-1356. https://doi.org/ 10.1111/bjet.13108

\section{Publisher's Note}

Springer Nature remains neutral with regard to jurisdictional claims in published maps and institutional affiliations.

\section{Submit your manuscript to a SpringerOpen ${ }^{\circ}$ journal and benefit from:}

- Convenient online submission

- Rigorous peer review

- Open access: articles freely available online

- High visibility within the field

- Retaining the copyright to your article

Submit your next manuscript at $\boldsymbol{\nabla}$ springeropen.com 